\title{
Effect of Postural Education on Physical Satisfaction and Life Habit in Elementary Students
}

\author{
Ju-Young Song \\ Department of Physical Therapy, Ulsan College, Ulsan, Korea
}

Purpose: This study was conducted to investigate the effect of postural education in preventive educational aspects on physical satisfaction and life habit related to posture in elementary school students.

Methods: Participants were 974 4th-grade elementary school students in 9 schools of $U$ city (boy 50.2\%, girl 49.8\%). Postural education was conducted from May through November 2011, once each semester, each class was conducted two times.

Results: Results of this study showed that physical satisfaction and life habit related to posture were significantly improved after postural education $(\mathrm{p}<0.05)$. Both physical satisfaction and life habit were not significantly difference between effort and non-effort group about good posture after education.

Conclusion: This study showed that postural education was effective in improving the physical satisfaction and life habit of elementary school students.

Keywords: Elementary student, Life habit, Physical satisfaction, Postural education

\section{서 론}

잘못된 생활습관과 불량한 자세는 척추에 변형을 초래할 수 있다. 불 량한 자세는 특히 빠르게 성장하는 아이들의 척추와 인대에 해로울 수 있으며, 척추의 변형이 비정상적으로 진행되어 좋지 못한 외형과 통증이나 경직을 동반하는 신체활동의 비유연성을 초래함으로써 정 신적인 문제를 유발할 수 있다. ${ }^{2}$

이러한 척추 문제는 특히 성장이 빠르게 진행하기 시작하는 사춘 기를 전후로 하여 발생하기 쉬운데, 2011년 건강보험심사평가원의 보 도 자료에 의하면, 2006년부터 2010년까지 척추 변형의 가장 흔한 형 태인 척추측만증을 주상병으로 하여 의료기관을 이용하였던 진료 인원이 10 만 3 천명에서 11 만 6 천명으로 5 년간 $12.2 \%$ 증가하였는데, 2010 년 자료에 의하면 10 대의 점유율이 $46.5 \%$ 로 가장 높았다. 또한 5 년간 척추측만증의 증가율이 10 대의 경우 $21.1 \%$ 로 증가하여 다른 연 령들에 비해서 가장 많이 증가한 것으로 나타났다. 척추측만증 학생 은 근지구력, 심폐지구력, 유연성이 떨어지고, ${ }^{4}$ 정적 균형능력이 떨어
지며, ${ }^{5}$ 보행시 앞발(forefoot)의 체중부하가 측만증이 없는 경우보다 높은 것 6 등의 신체적인 문제를 보이며, 스트레스 지수가 높은 것으로 나타났다?

척추변형이 심해져서 통증이 발생하면 정신건강과 사교활동에도 부정적인 영향을 미치게 되며, ${ }^{8}$ 외모의 변화로 신체적으로나 정신적 으로 급성장하는 청소년들에게 자아정체성과 같은 심리적 요인과 삶 의 질에 부정적인 영향을 미칠 수 있다. ${ }^{9}$

초등학교 고학년 시기는 신체적인 성장뿐만 아니라 자아에 대한 정체성과 함께 자신의 신체외모에 대한 관심이 높아지는 전사춘기에 해당하며, 일부 학생들은 사춘기에 들어가는 시기이다. 이 시기에 부 정적인 외모상과 신체상이 고착되면 열등감을 조성하고, 대인관계에 서 자신감이 저하되는 등의 문제를 초래할 수 있으며, 이러한 문제는 청소년기를 거쳐 청년기 이후에까지도 지속될 수 있다. ${ }^{10}$ 자신의 신체 에 대한 역기능적이고 부정적인 믿음과 감정은 다양한 심리 정서적 문제를 유발해서 청소년들의 신체와 정신건강을 위협하는 요인이 될 수 있다.11
Received January 8, 2015 Received February 5, 2015

Accepted February 9, 2015

Corresponding author Ju-Young Song

E-mail jysong@uc.ac.kr
Copylight $(2015$ The Korean Society of Physical Therapy

This is an Open Access article distribute under the terms of the Creative Commons Attribution Non-commercial License (Http:// creativecommons.org/license/by-nc/3.o.) which permits unrestricted non-commercial use, distribution, and reproduction in any medium, provided the original work is properly cited.

- The present research has been conducted by the research grant of Ulsan college in 2011. 
신체만족도와 관련된 대부분의 연구는 신체 및 외모만족도가 자 아존중감, ${ }^{12-15}$ 학교생활 부적응, ${ }^{15}$ 주관적 안녕감 ${ }^{10}$ 등에 미치는 영향 을 조사한 것이었으며, 신체만족도에 영향을 미치는 요인에 대한 연 구로는 자신의 신체 이미지에 대한 인식 정도, ${ }^{16}$ 자세와 운동참여에 관한 연구가 있다. ${ }^{17}$

자세가 좋을수록, 바른 자세를 취하는 사람일수록 신체만족도가 높았으며, ${ }^{17}$ 자세는 외모를 평가하고 개선하는데 있어 중요한 요인이 기 때문에 바른 자세를 취하는 것만으로도 훨씬 매력적으로 신체를 지각하게 된다고 한다.18

따라서 대부분의 학생이 아직 사춘기에 이르지 못해서 신체상에 대한 확립이 되어 있지 않고, 신체적 성장이 빠르게 진행되기 시작하 면서 잠재적인 척추의 문제를 보이기 시작하는 시점인 초등학교 고 학년생을 대상으로 자세교육을 실시하는 것은 척추의 변형을 예방 하는 것뿐만 아니라 아동의 심리 정서적 측면과 생활습관의 관리에 있어서 매우 중요한 일이다.

Cardon 등 ${ }^{19}$ 은 전청소년기(preadolescence)에 척추건강 교육을 실시 함으로써 청소년기 이후에 발생할 수 있는 자세문제를 예방할 수 있 다고 하였으며, Shin 등 ${ }^{20}$ 이 초등 7차 교육과정과 기존의 운동관련 사 이트를 분석하여 초등학생 때부터 스스로 건강과 운동의 중요성을 인식하고 관리할 수 있도록 IT 환경을 기반으로 한 콘텐츠를 개발한 내용에도 바른 자세 부분이 포함되어 있다. 또한 척추 변형으로 인해 발생할 수 있는 잠재적인 심리적, 정서적, 행동적 문제들을 예방하기 위해 측만증의 조기 발견 및 예방, ${ }^{21}$ 그리고 일상생활 및 잘못된 습관 에 대한 교육과 예방이 강조되고 있다.22

그러나 아동청소년기의 자세와 관련된 대부분의 연구는 특정한 운동이나 치료적 중재를 통해 자세가 어떻게 개선되었는지에 대한 것이 대부분이며, 예방 교육적 측면에서의 자세교육을 다루거나, 이 러한 자세교육이 아동들의 신체 만족도와 생활습관에 어떤 영향을 미치는지에 대한 연구는 거의 없는 실정이다.

이에 본 연구는 또래들과의 활동량이 많고 성장이 급격히 진행되 기 시작하는 초등학교 4학년생을 대상으로 척추의 변형을 예방하고 올바른 자세에 대한 인식을 개선하기 위하여 자세교육을 실시하고 신체 균형을 위한 운동프로그램을 지도함으로써 이러한 자세교육프 로그램이 초등학교 아동들의 신체만족도와 자세 관련 생활습관에 어떤 영향을 미치는지 알아보고자 하였다.

\section{연구방법}

\section{1. 연구대상}

본 연구는 $\mathrm{U}$ 시의 북구보건소와 강북교육지원청의 협조를 받아 북구 지역 관내에 소재하고 있는 19 개 초등학교에 자세교육 및 본 연구의
Table 1. Characteristic of subjects and satisfaction and opinion of postural education

\begin{tabular}{llc}
\hline & \multicolumn{1}{c}{ Contents } & Frequency (\%) \\
\hline Gender & Male & 50.2 \\
& Female & 49.8 \\
Satisfaction with education & Very satisfied & 23.1 \\
& Satisfied & 42.1 \\
& Moderate & 33.1 \\
& Dissatisfied & 0.9 \\
Preferred content & Very dissatisfied & 0.8 \\
& Information about good/ & 60.3 \\
For health & poor posture & \\
& Postural exercise & 39.7 \\
& Helpful & 58.3 \\
& Moderate & 39.6 \\
Trying to get a good posture & Eot helpful & 2.1 \\
& Effort & 77.5 \\
& Non effort & 22.5 \\
\hline
\end{tabular}

목적, 방법, 취지를 설명하는 의뢰 공문을 발송하였다.

자세교육과 연구에 동의한 초등학교는 9 개 학교로, 학교운영위원 회를 통하거나 가정통신문을 이용하여 학부모에게 자세교육 일정을 알리고 동의를 구하였다.

전체 9 개 초등학교의 4 학년 39 개 학급을 대상으로 총 1,050 명의 학 생들에게 자세교육을 실시하였으나, 전학을 갔거나 전학을 와서 사 전 자료와사후 자료를 모두 취합할 수 없었던 경우와 교육 전 설문지 나 교육 후 설문지에 충실히 응답하지 않은 경우를 제외하고 최종 974명의 자료를 분석 대상으로 하였다. 연구대상자는 남자가 489 명 (50.2\%), 여자가 485명(49.8\%)이었다(Table 1).

\section{2. 자료수집 기간 및 방법}

초등학교에 자세교육 프로그램 및 연구에 대한 의뢰 공문을 보내고, 교육을 희망하고 연구에 동의한 학교를 대상으로 하였다. 2011년 5월 부터 11 월 말까지 각 학급별로 학기마다 1회씩, 회기 당 40 분간, 총 2 회 자세교육을 실시하였다. 자세교육 및 설문을 위한 방문 시간은 해 당 학교 담당 교사와 일정을 논의하여 학생들의 수업시간을 이용하 였다.

1 차 자세교육(1학기)을 실시하기 이전에 해당 학교를 직접 방문하 여 학생들에게 사전 설문지를 배부하고 수거하였으며, 2 차 교육(2학 기)이 완료된 이후에 사후 설문지를 배부 및 수거하여 분석에 이용하 였다. 설문지를 작성하는 방식은 자가기입식이었는데, 연구자가 설문 지 작성법에 대해 전체적으로 설명하고, 문항과 관련된 질문에 언제 든지 응답할 수 있도록 설문이 끝날 때까지 교실에 상주하는 방식으 로 진행하였다. 


\section{3. 측정 도구 및 내용}

본 연구에서 이용한 신체만족도 검사는 신체 각 부분과 기능에 대한 만족도를 측정하기 위한 것으로 $\mathrm{Kim}^{15}$ 의 설문지를 사용하였다. 22 개 문항 중 15 개 문항은 신체조건에 대한 것이며(예, 피부, 키, 체격, 머리 크기, 얼굴의 전체 모양 등), 7 개 문항은 신체강도에 대한 것이다(예, 힘, 팔의 힘, 다리 힘, 민첩성, 운동능력 등). 5 점 척도로 되어 있어 '매 우 불만이다'는 1점, '불만이다는 2점, '보통이다는 3점, '만족한다'는 4 점, '매우 만족한다'는 5점으로 점수가 높을수록 자신의 신체에 대해 만족하는 것을 의미한다. 본 연구에서 신체만족도 검사의 응답일치 도의 Cronbach's $\alpha=0.935$ 였다.

생활습관은 평상시 자세와 관련된 내용을 9 개 문항, 3 점 척도로 구 성하였다. 불량한 자세를 자주 취하는 편이면 1점, 보통이면 2점, 전혀 취하지 않으면 3점에 체크하도록 되어 있어서, 점수가 높을수록 자세 관련 생활습관이 양호한 것을 의미한다. 본 연구에서 생활습관 조사 의 응답일치도의 Cronbach's $\alpha=0.644$ 였다.

\section{4. 자세교육 프로그램}

자세교육은 본 연구자(주 강사)와 본 연구자의 지도를 받은 물리치료 과 학생들이 보조강사로 참여하여 진행되었으며, 한 학급에 본 연구 자와 대학생 1-2명 함께 들어가서 강의를 진행하였다. 주 강사는 자세 교육 전반을 진행하였으며, 보조강사는 교육 시 주의가 산만하거나 태도가 불량한 학생을 지도하고, 운동지도 시 주 강사의 손이 미치지 않는 곳의 학생들을 대상으로 정확한 동작이 수행되도록 지도하는 역할을 하였다.

자세교육 프로그램은 학생들로 하여금 척추측만증과 같은 척추변 형에 대해 인지하고 이를 예방하기 위해 생활 속에서 바른 자세를 취 하고 적절한 신체 활동을 할 수 있도록 하는 예방적 차원에서의 교육 이었다. 교육 내용은 크게 이해교육과 운동지도로 구성되었다. 이해 교육은 올바른 자세의 중요성, 척추측만증이 무엇인지, 일상생활 속 에서 나쁜 자세에는 어떤 것이 있는지, 일상생활과 관련하여 바른 자 세를 취하는 방법을 다루었으며, 파워포인트를 이용하여 약 20 분 정 도 시행하였다.

운동지도는 동작을 동영상으로 제작하였는데, 학교 교실이라는 제한된 공간에서 쉽게 수행할 수 있도록 앉은 자세와 선 자세에서의 운동을 주로 하였으며, 쉬는 시간이나 조례 시간 등을 이용하여 자주 수행할 수 있도록 운동내용을 8 분 23 초 분량으로 제작하여 자세교육 시 VTR를 통해 동영상을 보면서 운동이 정확히 수행되도록 지도하 였다. 그리고 자세교육 시 수행한 운동에 덧붙여 누운 자세에서의 동 작을 포함한 운동 자료를 책받침으로 만들어 학생들에게 배부하였 다(Figure 1).

운동지도는 신장과 근력강화를 통해 신체의 전후, 좌우 균형과 대

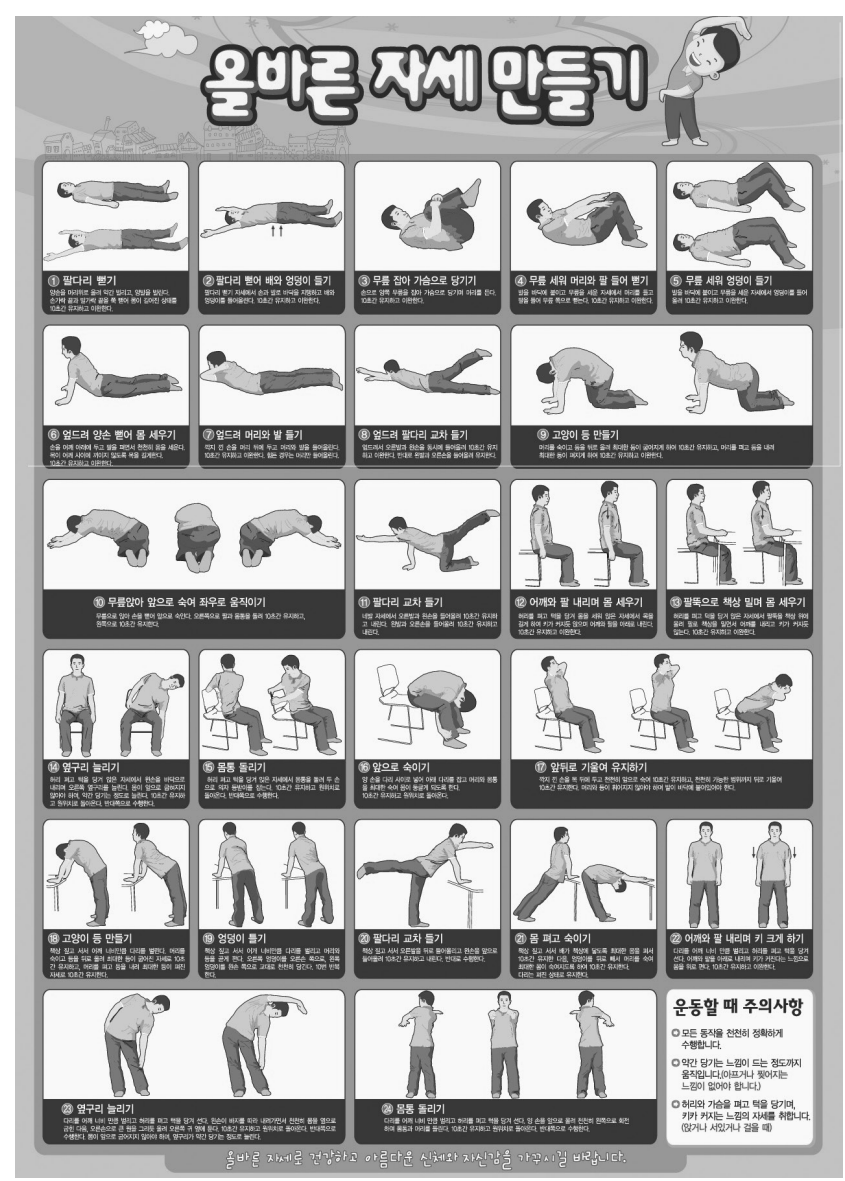

Figure 1. Poster of postural exercise.

칭적인 신체 발달을 촉진하기 위한 목적으로, 척추를 곧게 한 상태에 서의 심호흡 운동, 척주 직선화 운동, 척추 회전운동, 요부안정화 운 동, ${ }^{5}$ 신장운동과 근력강화 운동을 주로 하여 내용을 구성하였다. 이 것은 척추측만증을 교정하는 운동방법으로 휘어지거나 기울어져 긴 장된 척추의 주변부분 근육을 풀어주는 운동, 척추를 곧고 바르게 펴 는 운동, 바르고 곧게 편 척추자세를 유지하도록 주변 근육을 보강하 는 운동을 단계적으로 제시한 선행 논문들을 참고로 한 것이다.23-25

운동 동영상에 포함된 앉은 자세에서 수행되는 동작으로는 허리 펴 고 턱을 당겨 앉아 심호흡 하기, 어깨 내리고 목 길게 하기(손 끝이 바 닥에 가까워지도록), 옆으로 굽히기, 몸통 돌리기, 앞으로 숙이기가 있 으며, 책상을 짚은 자세에서는 고양이 등 만들기, 엉덩이 틀기, 팔다리 교차 들기, 몸 펴고 숙이기가 있었고, 똑바로 선 자세에서는 옆구리 펴 기(옆구리 늘리기)와양손 앞으로 올려 뒤로 회전하기 동작이 있었다.

\section{5. 자료 분석}

자료 분석은 PASW 18.0 프로그램을 이용하였다. 연구대상자의 일반 적 특성과 자세교육에 대한 견해를 알아보기 위해 기술통계와 빈도 
분석을 실시하였으며, 자세교육 전과 후에 신체만족도와 생활습관 의 변화를 알아보기 위하여 대응표본 $\mathrm{t}$ 검정을 수행하였다. 1 차 교육 이후 바른 자세로 생활하려고 노력한 유무에 따라 차이가 있는지 알 아보기 위하여 독립표본 $\mathrm{t}$ 검정을 수행하였다. 유의수준은 0.05 로 하 였다.

\section{결 과}

\section{1. 자세교육에 대한 만족도 및 견해}

자세교육 프로그램에 대해 얼마나 만족하는지 알아본 결과, 응답한 학생의 $23.1 \%$ 가 '매우 만족 한다', $42.1 \%$ 가 '만족 한다'로 응답하여, $65.2 \%$ 의 학생이 만족하는 것으로 나타났다. 반면에 '불만족 한다'와 '매우 불만족 한다'는 각각 $0.9 \%$ 와 $0.8 \%$ 로 매우 낮게 나타났다. 교육 내용 중에서 선호하는 것으로는 좋은 자세와 나쁜 자세에 대해 알게 된 것'이라고 응답한 경우가 $60.3 \%$ 였으며, $39.7 \%$ 는 '자세운동을 배운 것'이라고 응답하였다. 그리고 자세교육이 '건강에 도움이 된다'고 생 각한 경우가 $58.3 \%$ 였으며, 단지 $2.1 \%$ 의 학생이 도움이 되지 않는다는 부정적인 의견을 보였다. 1 차 교육을 받은 이후에 바른 자세로 생활 하려고 노력하였는지 알아본 결과, 학생의 $77.5 \%$ 가 '노력하였다'고 응 답하였으며, $22.5 \%$ 는 ‘노력하지 않았다고 응답하였다(Table 1).

Table 2. Comparison of physical satisfaction

\begin{tabular}{ccccc}
\hline & \multicolumn{2}{c}{ Physical education } & \multirow{2}{*}{$\mathrm{t}$} & $\mathrm{p}$ \\
\cline { 2 - 3 } & Before & After & & \\
\hline Physical satisfaction & $3.53 \pm 0.64$ & $3.56 \pm 0.64$ & -1.987 & $0.047^{*}$ \\
Physical condition & $3.50 \pm 0.66$ & $3.55 \pm 0.65$ & -2.449 & $0.015^{*}$ \\
Physical strength & $3.59 \pm 0.83$ & $3.59 \pm 0.82$ & -0.393 & 0.694 \\
\hline
\end{tabular}

${ }^{*} p<0.05$.

Table 3. Comparison of life habit associated with posture

\begin{tabular}{|c|c|c|c|c|}
\hline & \multicolumn{2}{|c|}{ Postural education } & \multirow{2}{*}{$\mathrm{t}$} & \multirow{2}{*}{$\mathrm{p}$} \\
\hline & Before & After & & \\
\hline Stands one foot when standing & $1.36 \pm 0.57$ & $1.45 \pm 0.60$ & -3.617 & $0.000^{*}$ \\
\hline Sleeping on one side & $2.19 \pm 0.71$ & $2.24 \pm 0.71$ & -2.124 & $0.034 *$ \\
\hline Tie the bag with one shoulder & $1.27 \pm 0.53$ & $1.32 \pm 0.55$ & -2.482 & $0.013^{*}$ \\
\hline $\begin{array}{l}\text { Bows at the waist when lifting } \\
\text { objects }\end{array}$ & $2.25 \pm 0.68$ & $2.20 \pm 0.68$ & 1.984 & $0.048^{*}$ \\
\hline $\begin{array}{l}\text { Continue to sit for at least } \\
1 \text { hour }\end{array}$ & $2.17 \pm 0.72$ & $2.31 \pm 0.69$ & -4.849 & $0.000 *$ \\
\hline Uphold the chin with one hand & $1.71 \pm 0.66$ & $1.75 \pm 0.67$ & -1.710 & 0.088 \\
\hline Walk out-toed gait & $1.25 \pm 0.51$ & $1.29 \pm 0.53$ & -2.451 & $0.014^{*}$ \\
\hline $\begin{array}{l}\text { Close to your face when you } \\
\text { see a books }\end{array}$ & $1.45 \pm 0.62$ & $1.51 \pm 0.63$ & -2.554 & $0.011 *$ \\
\hline Sit with one's legs crossed & $1.53 \pm 0.68$ & $1.53 \pm 0.66$ & -0.186 & 0.853 \\
\hline Mean & $1.69 \pm 0.32$ & $1.73 \pm 0.32$ & -4.655 & 0.000 * \\
\hline
\end{tabular}

${ }^{*} p<0.05$.

\section{2. 신체만족도 비교}

자신의 신체에 대해서 스스로 어떻게 생각하는지 알아본 결과, 자세 교육 전에 3.53점에서 교육 후 3.56점로 만족도가 유의하게 증가한 것 으로 나타났다 $(\mathrm{p}=0.047)$. 신체만족도를 신체조건과 신체강도에 대한 것으로 세분하여 알아본 결과, 신체조건의 경우, 교육 전 3.5 점에서 교 육 후 3.55점으로 유의하게 향상된 것으로 나타났다 $(\mathrm{p}=0.015)$. 반면 에 신체강도에 대한 만족도는 교육 전과 교육 후 둘 다 3.59점으로 나 타나 통계적으로 유의한 차이가 없었다 $(\mathrm{p}=0.694)$ (Table 2).

\section{3. 생활습관 비교}

자세와 관련된 평상시의 생활습관에 대해서 자세교육 전과 후에 어 떤 변화가 있었는지 알아본 결과, 교육 전에는 1.69 점에서 교육 후 1.73 점으로 나타나, 자세와 관련된 생활습관이 교육 후 유의하게 향상된 것으로 나타났다 $(\mathrm{p}<0.001)$ (Table 3).

세부항목으로는 서 있을 때 한쪽 발로 선다', '잠잘 때 옆으로 누워 잔다, '한쪽 어깨로 가방을 맨다, ' 1 시간 이상 오랫동안 지속적으로 앉 아 있는다', '팔자 걸음을 걷는다', '컴퓨터나 책을 볼 때 얼굴을 가까이 한다'에서 생활습관이 유의하게 개선된 것으로 나타났다 $(\mathrm{p}<0.05)$. 반 면에 '한 손으로 턱을 괴고 앉는다'와 '다리를 꼬고 앉는다'는 자세교 육 이후 개선되지 않은 것으로 나타났으며(p>0.05), '바닥에 물건을 주울 때 허리를 숙인다 항목은 자세교육 이후 오히려 불량해진 것으 로 나타났다 $(\mathrm{p}=0.048)($ Table 3$)$.

\section{4. 바른 자세 노력 유무에 따른 비교}

신체만족도와 생활습관이 1 차 교육 이후 바른 자세로 생활하려고 노 력한 군과 노력하지 않은 군 간에 차이가 있는지 알아보았다.

신체만족도는 자세 교육을 수행하기 전에 바른 자세로 생활하려 고 노력한 그룹(노력 군)이 3.59점으로 노력하지 않은 그룹(비노력 군) 의 3.34 점보다 유의하게 높은 것으로 나타났다 $(\mathrm{p}<0.001)$. 반면에 생 활습관은 노력 군이 1.65 점, 비노력 군이 1.81 점으로 비노력 군의 생활

Table 4. Comparison between effort and non-effort group

\begin{tabular}{ccccc}
\hline & & \multicolumn{3}{c}{ Postural education } \\
\cline { 3 - 5 } & & Before & After & After-Before \\
\hline Physical & Effort & $3.59 \pm 0.65$ & $3.61 \pm 0.64$ & $0.02 \pm 0.55$ \\
satisfaction & Non-effort & $3.34 \pm 0.61$ & $3.39 \pm 0.62$ & $0.05 \pm 0.55$ \\
& $\mathrm{t}$ & 5.099 & & -0.531 \\
& $\mathrm{p}$ & $0.000 *$ & & 0.596 \\
Life habit & Effort & $1.65 \pm 0.31$ & $1.7 \pm 0.31$ & $0.05 \pm 0.31$ \\
& Non-effort & $1.81 \pm 0.33$ & $1.84 \pm 0.32$ & $0.03 \pm 0.30$ \\
& $\mathrm{t}$ & -6.683 & & 1.076 \\
& $\mathrm{p}$ & $0.000 *$ & & 0.282 \\
\hline
\end{tabular}

${ }^{*} p<0.05$ 
습관이 유의하게 높은 것으로 나타났다 $(\mathrm{p}<0.001)$.

따라서 신체만족도와 생활습관을 교육 후 값에서 교육 전 값을 뺀 차이 값을 이용해서 노력군과 비노력 군 간에 비교하였다. 그 결과, 신 체만족도와 생활습관 모두 노력 유무에 따른 차이는 없는 것으로 나 타났다 $(\mathrm{p}=0.596)(\mathrm{p}=0.282)($ Table 4).

\section{고 찰}

자신의 외모에 대한 만족도가 낮고 자존감이 낮으면 행복감이 상당 히 저하되는 반면에, ${ }^{12}$ 이에 대한 만족도가 높은 초등학생은 그렇지 못한 학생들보다 자아존중감이 높고 학교생활에 대한 부적응 정도 가 낮은 것으로 나타났다. ${ }^{13}$ 신체 외모에 대한 만족도에 영향을 미치 는 요인으로 자세와 관련된 연구가 있는데, 이 연구에 의하면 신체 자 세가 좋을수록 신체이미지가 긍정적으로 형성되고 자아존중감이 높다고 한다. ${ }^{17}$

본 연구는 전청소년기에 해당하는 초등학교 4 학년생들을 대상으 로 올바른 자세에 대한 이해교육과 운동지도를 실시함으로써 자세 교육이 신체만족도와 자세관련 생활습관에 미치는 영향을 알아보 고자 하였다. 자세교육은 개별 학급당 1 학기와 2 학기에 각각 1 회씩 2 회 실시되었다.

자세교육 이후 $65.2 \%$ 의 학생이 교육에 만족한다고 하였으며, $1.7 \%$ 의 학생만이 불만족하는 것으로 나타났다. 또한 $58.3 \%$ 의 학생은 자세 교육이 건강에 도움이 된다는 의견을 보여 과반수 이상의 학생들이 자세교육을 긍정적으로 생각하는 것으로 파악되었다. 1 차 교육 이후, $77.5 \%$ 의 학생이 바른 자세로 생활하려고 노력한 것으로 나타나, 단발 적인 자세교육을 통해서도 바른 자세의 중요성과 필요성이 학생들에 게 대체로 잘 전달된 것으로 파악되었다.

자신의 신체적 외모와 관련된 자신의 태도, 지각, 경험을 포함하는 것을 신체상이라 하는데, ${ }^{26}$ 신체만족도는 신체상과 관련된 것이다. 본 연구에서 신체만족도는 자세교육 이후 다소 향상된 것으로 나타났 다. 신체만족도 중에서 신체강도는 유의한 변화가 없었으나, 신체조 건에 대한 항목에서는 유의한 향상이 있었던 것으로 나타났다. 이것 은 신체의 건강과 강인함을 의미하는 신체강도보다는 자세교육이 몸을 바로 세우고 펴는 자세와 관련되기 때문에 신체가 어떻게 보여 지는지에 대한 신체 조건에 더 많은 영향을 미친 것으로 생각된다.

자세가 좋을수록 신체만족도가 높았다는 Jun ${ }^{17}$ 의 연구와 신체 이 미지에 대한 긍정적인 인식을 갖고 있는 사람이 신체에 대한 만족도 가 높았다는 연구 ${ }^{12}$ 를 고려해 볼 때, 본 연구에서 자세교육 이후 학생 의 $77.5 \%$ 가 바른 자세를 취하기 위해 노력하였고, $58.3 \%$ 의 학생이 자 세교육이 건강에 도움에 된다고 응답한 것으로 보아, 자세교육이 초 등학생들로 하여금 바른 자세를 취함으로써 신체 균형과 건강을 도
모할 수 있다는 긍정적인 믿음을 주고 이것이 신체만족도의 향상에 기여한 것으로 보인다. 이것은 $\mathrm{Oh}^{27}$ 의 연구에서 초등학교 4학년 학생 의 신체만족도가 아동의 건강 행동과 관련이 되며, 아동 스스로가 지 각하는 자신의 건강상태가 건강행동과 신체만족도에 영향을 줄 수 있다는 결과와 유사하다.

자세와 관련된 평상시의 생활습관이 자세교육의 영향을 받았는 지 알아본 결과, 자세교육 이후 생활습관이 유의하게 향상된 것으로 나타났다. 이는 척추 건강교육 이후 척추 건강지식이 향상되었다는 연구 ${ }^{28-30}$ 와 관련되는 것으로 보이며, 바른 자세에 대한 지식 점수와 생활습관 간에 유의한 상관관계가 있다는 연구 ${ }^{31}$ 와 관련되는 것으로 보인다. 또한 10.7 세 아동 137 명을 대상으로 6주 동안 6번의 자세교육 을 실시한 Vidal 등 32 의 연구에서 자세교육을 받은 실험군이 건강 습 관점수(health habit score)가 유의하게 증가하고, 이것이 3개월 이후에 도 여전히 유의하게 향상되어있었다는 연구 결과와 유사하다. Cardon 등 ${ }^{33}$ 의 연구에서도 6주간 주 1회씩 총 6회 초등학교 4-5학년 학생 들을 대상으로 등(back) 자세관리 교육을 실시한 결과, 등 자세관리 지식이 유의하게 향상되었다고 보고하였다. Geldhof 등 34 은 9-11세 아 동 365명을 대상으로 교실 내에서 자세교육을 실시하고 자세 활력을 자극하는 다인성 중재(multifactorial intervention)를 적용하였는데, 그 결과 자세지식이 증가하고 사물을 다루는 동안 자세행동이 개선되 었다고 보고하였다. 본 연구에서도 자세와 관련된 생활습관 9 가지 중 6 가지가 개선되었으며 2가지는 유의한 변화가 없었던 것으로 나타나 전반적으로 생활습관의 세부항목들이 개선된 것으로 보인다. 그러 나 '바닥의 물건을 들어올릴 때 허리를 숙인다'는 항목은 교육 전과 후의 차이 값이 0.05 에 불과하지만 불량해진 것으로 나타나, Geldhof 등 $^{33}$ 의 연구 결과와 상반된다. 이는 본 연구의 교육 회기가 짧아서 정 적인 자세를 수정하는 데에는 도움이 되었지만 상대적으로 빠르게 수행되는 동적 동작의 수정에는 미흡한 점이 있는 것으로 생각된다.

본 연구의 제한 점으로는 자세교육 이후 학교와 가정에서의 자세 운동 및 바른 자세 실천에 대한 사항을 학생들의 자가 응답에 의존하 였으며, 사후관리에 대한 독려와 점검이 부족하였다는 것, 참고할 만 한 선행논문이 부족하였다는 것을 들 수 있다.

본 연구의 결과, 초등학생을 대상으로 한 예방적 자세교육 프로그 램이 학생들의 신체만족도를 향상시키고 자세 관련 생활습관을 개 선하는데 도움이 된 것으로 나타났다. 이에 본 연구가 학교 보건교육 에서의 자세교육과 프로그램 개발 및 정책 개발을 위한 기초자료로 활용될 수 있을 것으로 사료된다. 앞으로 학교보건에서 자세교육 프 로그램의 효과적이고 효율적인 운영방안에 대한 연구와 모든 초등학 생들이 학교를 통해 자세를 관리 받고 자세교육을 받을 수 있는 정책 적 방안에 대한 연구가 요구될 것으로 보인다. 


\section{ACKNOWLEDGEMENTS}

The present research has been conducted by the research grant of Ulsan college in 2011.

\section{REFERENCES}

1. Smith DR, Leggat PA. Back pain in young: A review of studies conducted among school children and university students. Curr Pediatr Rev. 2007;3:69-77.

2. Chung KJ. Prevalence of adolescent idiopathic scoliosis through school screening. Korea University. Dissertation of Doctorate Degree. 2007.

3. Health Insurance Review \& Assessment Service, 2010:1-5.

4. Lee CH, Jeong YT, Kim HC, et al. Comparison of physique, physical fitness and mental health between spinal scoliosis and normal students. Korean J Growth and Develop. 2006;14(2):87-94.

5. Shin SS, Song CH. The effect of lumbar stabilization exercise on the balance of adolescent idiopathic scoliosis. Korean J Sports Med. 2007;25(2): $165-73$.

6. Kim SH, Kim HJ. Changes in gait parameter with adolescent idiopathic scoliosis. J Kor Phys Ther. 2014;26(3):136-9.

7. Hong YJ, Cho SH, Hwang BK. The influence of adolescent's scoliosis on stress and study-attitude. J Kor Phys Ther. 2012;24(1):15-21.

8. Jensen MP, Hoffmean AJ, Cardenas DD. Chronic pain in individuals with spinal cord injury: A survey and longitudinal study. Spinal Cord. 2005;43(12):704-12.

9. Kim SJ. A study of intervention for adolescent idiopathic scoliosis. J Kor Phys Ther. 2004;16(1):35-44.

10. Kim JH, Lee JY. The effects of children's appearance satisfaction upon their subjective well-being with rejection sensitivity as a mediating factor. J Korea Institute Youth facility Environ. 2010;8(3):3-14.

11. Chyung YJ. The mediating effects of body comparison on the relationship between internalization of sociocultural attitudes toward appearance and body dissatisfaction among adolescent girls. Korean J Child Studi. 2013;34(2):27-42.

12. Shim WY. Mediation effects of self-esteem in the relationship between appearance satisfaction and happiness of elementary school students. J Elemen Edu. 2012:25(4):31-51.

13. Lee YS, Lee GL. The relationship among appearance satisfaction, self-esteem and school maladjustment in elementary, middle, and high school students. J Korean Soc School Health. 2008;21(1):11-22.

14. Han SS. Relationships between elementary school student's appearance recognition and satisfaction on self-concept and mental health. Chuncheon National University of Education. Dissertation of Master's Degree. 2006.

15. Kim YK. The relationship between appearance satisfaction, physical satisfaction and self-esteem, school maladjustment of children. Chuncheon National University of Education. Dissertation of Master's Degree. 2005.
16. Jun KR, Lee MH. The influence of body satisfaction and psychological characteristics on appearance elevation attitude. J Korean Soc Clothing Textiles. 2003;27(6):643-53.

17. Jun SH. The relationship between posture and exercise habit, life style, physical satisfaction. J Korean Phys Edu Assoc Girls Women. 2004; 18(4):81-91.

18. Yum EY, Shin SJ. A qualitative approach to the effect of self-portraits in the understanding on body image. Soc Korean Photo. 2006;15:100-11.

19. Cardon G, De Clercq DLR, Geldhof E, et al. Back education in elementary schoolchildren: The effects of adding a physical activity promotion program to a back care program. Eur Spine J. 2007;16:125-33.

20. Shin SH, Lee BK, Woo JH, et al. PAPS contents development for elementary school students. J Korea Contents Assoc. 2011;11(9):96-105.

21. Yu JH, Jung SM. Effects of conservative treatment on scoliosis according to early detection. J Kor Phys Ther. 2010;22(4):65-71.

22. Lee MH, Song JM, Kim JS. The effect of neck exercise on neck and shoulder posture and pain in high school students. J Kor Phys Ther. 2011;23(1):29-35.

23. Geldhof E, Cardon G, De Bourdeaudhuij I, et al. Back posture education in elementary schoolchildren: A 2-year follow-up study. Eur Spine J. 2007;16:841-50.

24. Heyman E, Dekel H. Ergonomics for children: An educational program for elementary school. Work. 2008;31:253-7.

25. Negrini S, Grivas TB, Kotwicki T, et al. Why do we treat adolescent idiopathic scoliosis? What we want to obtain and to avoid for our patients. SOSORT 2005 Consensus paper. Scoliosis, 2006:1-14.

26. Cash TF, Pruzinskyu T. Body image: A handbook of theory, research, and clinical practice. New York, Guilford, 2002.

27. Oh JA. Relationship of body satisfaction, self-rated health, and parentchild attachment to health behavior of children as perceived by 4 th grade elementary school students and their mothers. J Korean Acad Child Health Nurs. 2011;17(3):161-6.

28. Steele EJ, Dawson AP, Hiller JE. School-based interventions for spinal pain: A systematic review. Spine. 2006;31:226-33.

29. Park JH, Kim JS. Effects of spinal health educational programs for elementary school children. J Spec Pediatr Nurs. 2011;16:121-9.

30. Geldhof E, Cardon G, De Bourdeaudhuij I, et al. Effects of back posture education on elementary school children's back function. Eur Spine J. 2006:Sep 30, Epub ahead of print.

31. Kim S, Kim JS. Knowledge of good posture and postural habits in elementary school children. Korean J Child Health Nurs. 2007;13(2): 18290.

32. Vidal J, Borras PA, Ortega FB, et al. Effects of postural education on daily habits in children. International J Sports Med. 2011;32(4):303-8.

33. Cardon G, De Clercq D, De Bourdeauhuij I. Effects of back care education in elementary schoolchildren. 2000;89:1010-7.

34. Geldhof E, Cardon G, De Bourdeaudhuij I. Effects of a two-school-year multifactorial back education program in elementary school children. Spine. 2006;31(7):1965-73. 